Filol. linguist. port., n. 14(1), p. 141-156, 2012.

\title{
Avaliação de julgamento no gênero notícia: duas notícias, duas propostas jornalísticas, um mesmo julgamento
}

\author{
Juliene Paiva de Araújo Osias ${ }^{1}$
}

\begin{abstract}
Resumo: Duas notícias, divulgadas em dois jornais de circulação local - Correio da Paraíba e Já Paraíba -, foram analisadas, tomando-se por base o sistema de avaliatividade, desenvolvido a partir dos princípios da Linguística Sistêmico-Funcional, mais especificamente, a categoria de julgamento (uma das regiões do subsistema atitude), no grupo da sanção social. Analisou-se o caráter avaliativo no âmbito de um gênero discursivo teoricamente narrativo, como também a ocorrência desse julgamento, havendo ou não o registro de variações linguísticas (aspecto ressaltado pelo fato de os dois jornais em questão serem de propostas linguísticas opostas), mediante uma leitura comparativa.
\end{abstract}

Palavras-chave: Atitude; Julgamento; Linguística Sistêmico-Funcional; Notícia; Sistema de Avaliatividade.

\section{INTRODUÇÃO}

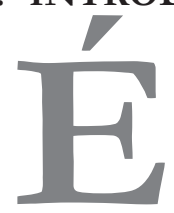

de amplo conhecimento da população paraibana que dois dos jornais de circulação diária no Estado - Jornal Correio da Paraíba e Já Paraíba - apresentam propostas diferentes para públicos opostos: o primeiro é um periódico tradicional no formato e na linguagem, em conformidade com aspectos típicos do gênero jornalístico, como o uso do padrão da língua, por exemplo. O segundo é uma publicação voltada para um público de poder aquisitivo mais baixo, e, consequentemente, vivência acadêmica parca ou inexistente.

1 Professora da Universidade Federal da Paraíba (UFPB); Mestre em Linguística pela UFPB; doutoranda em Linguística pelo PROLING (UFPB). E-mail: julieneosias@ gmail.com- 
Inicialmente, selecionamos (Quadrilha explode banco em Alagoinha) no Jornal Correio da Paraíba (caderno B6) e outra (Choveu dinheiro em Alagoinha) - de tema idêntico - no Já Paraíba (seção Cidades), ambas publicadas em 13 de julho de 2011.

Nosso objetivo principal é realizar uma leitura comparativa entre as duas notícias, considerando que ambas tratam do mesmo assunto: a explosão de caixas eletrônicos em uma certa agência do Bradesco, localizada em Alagoinha.

Nosso objetivo específico é a análise da avaliação do julgamento - uma das categorias semânticas de Atitude (um subsistema do sistema de avaliatividade) - presente nos textos.

Far-se-á uso de uma metodologia com base em leituras comparativas, inserindo-se os conhecimentos acerca de Atitude para análise das citadas notícias.

Na fundamentação teórica, exporemos, principalmente, os conceitos de sistema de avaliatividade, atitude e julgamento, como também esclareceremos, basicamente, a formação e a proposta dos jornais Correio da Paraíba e Já Paraíba, o corpus para este artigo.

Nas considerações finais, retomaremos o que foi discutido acerca do corpus no que diz respeito à presença ou à ausência de avaliação de julgamento, subentendidas ou não na concretização do discurso, além de questões acerca da variação linguística dentro do gênero notícia, considerando-se, ainda, a configuração e a funcionalidade social deste gênero.

\section{O SISTEMA DE AVALIATIVIDADE}

O sistema de avaliatividade, desenvolvido a partir dos princípios da Linguística Sistêmico-Funcional, refere-se ao modo como os interlocutores na expressão verbal tanto oral quanto escrita - expressam sentimentos, pontos de vista e atitudes sobre situações, pessoas, objetos, fenômenos, entre outros, e associa-se aos sentidos interpessoais gerados no texto por essas expressões, uma vez que, nas relações interpessoais, os interlocutores exteriorizam avaliações de afeto e de comportamento, além da apreciação de coisas, eventos, situações. 
Essas avaliações podem ocorrer de modo implícito, sendo sugestivo, portanto, compreendido nas entrelinhas, ou de modo explícito, textual, concretizado no discurso, seja com conotação positiva ou negativa.

Tal sistema compõe-se de três subsistemas que atuam paralelamente: atitude, engajamento e gradação, e será o subsistema atitude o nosso foco.

Sobre o subsistema atitude, vejamos a definição abaixo:

A atitude é o subsistema do sistema de avaliatividade responsável pela expressão linguística das avaliações positivas e negativas, que abrange três regiões semânticas: a emoção, a ética e a estética. A saber, avaliações de afeto, julgamento e apreciação. [...] A expressão da atitude ocupa um lugar central no processo avaliativo ao revelar os tipos e níveis em que a avaliação é desenvolvida e expressa no discurso. Para Martin e Rose (2003, p.22): "Atitudes têm a ver com a avaliação das coisas, do caráter das pessoas e seus sentimentos. Tais avaliações podem ser mais ou menos intensas, isto é, elas podem ser mais ou menos ampliadas". (ALMEIDA, 2011, p. 99-100)

A região afeto denota as emoções expressas pelos interlocutores. Julgamento é a região do subsistema atitude em que os falantes exteriorizam pontos de vista acerca do comportamento humano e, por fim, apreciação é a categoria através da qual se constroem avaliações acerca de coisas, objetos e fenômenos.

Quando abordamos atitude,

estamos preocupados com aqueles enunciados que podem ser interpretados como indicativos do modo como uma pessoa, coisa, situação, ação, evento ou estado de coisas são vistos tanto positiva como negativamente. Isso quer dizer que nós classificamos qualquer enunciado como atitudinal quando ele carrega uma avaliação positiva ou negativa ou quando pode ser interpretado como um convite para que o leitor insira sua própria avaliação negativa ou positiva. (WHITE, 2001 apud LIMA e COROA, 2010, p. 128)

À guisa de complemento para a conceituação do sistema atitudinal, é interessante mencionar o resumo realizado por SOPHIE (2008, p. 59) apud LIMA e COROA (2010):

No sistema de Afeto, as avaliações são agrupadas em três conjuntos principais: in/felicidade, in/segurança e in/satisfação (Martin e White, 2005, p. 49): 
- Os significados relacionados à in/felicidade compreendem as reações emocionais internas de alegria ou tristeza.

- Os significados relacionados à in/segurança compreendem nossos sentimentos de paz e ansiedade com relação ao ambiente que nos rodeia.

- Os sentimentos relacionados à in/satisfação compreendem os sentimentos de realização de metas e frustração.

No sistema de Julgamento, as avaliações estão agrupadas em dois conjuntos principais, estima social e sanção social.

- Os significados relacionados à estima social são classificados em: normalidade (a oposição entre normal/diferente), capacidade (capaz/ incapaz) e tenacidade (resoluto/titubeante).

- Os significados relacionados à sanção social são classificados em: veracidade (confiável/não confiável) e propriedade (ético/não ético)

No sistema de Apreciação, as avaliações estão agrupadas em:

- Reação (interessante/desinteressante).

Composição (harmônico/desarmônico, consistente/inconsistente etc.).

- Valor (valioso/não valioso). (SOPHIE, 2008, p. 59 apud LIMA e COROA, 2010, p. 129)

Cumpre frisar que a conceituação mais abrangente do subsistema atitude realizada até aqui (principalmente no resumo citado) - em seus conceitos voltados à afetividade (sistema de Afeto) e à estética (sistema de Apreciação) - já cumpriu sua meta. Restringir-nos-emos, a partir de agora, ao foco pretendido: julgamento.

\subsection{Julgamento}

Baseados em ALMEIDA (2011), tomamos julgamento como a categoria que se refere à postura atitudinal adotada pelos interlocutores em relação ao comportamento humano, de forma a julgar outrem, tomando-se como parâmetros certas normas sociais de conduta acerca do que é certo ou errado, adequado ou inadequado, aceitável ou inaceitável, ultrajante ou não ultrajante, excessivo ou não excessivo - ou seja, as avaliações podem ser de caráter positivo ou negativo.

A natureza dos julgamentos pode variar de pessoal a moral. Se pessoal, o julgamento ocorrerá no âmbito da admiração ou da crítica; se moral, no do 
mérito ou da condenação. A partir, então, desses direcionamentos, delimitemos os dois grupos de julgamento: estima social e sanção social.

Estima social é uma vertente que comporta avaliações - sem conotações legais ou morais - capazes de prestigiar ou desprestigiar o alvo da avaliação no âmbito da comunidade. São legais e morais, em contrapartida, as avaliações realizadas na vertente sanção social quanto ao comportamento alheio no convívio social.

O grupo da estima social apresenta a subdivisão ilustrada abaixo:

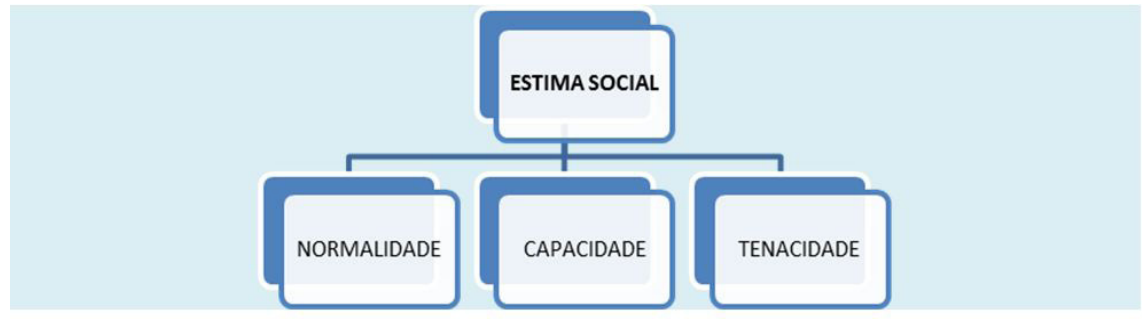

Fonte: Osias, 2011.

Entenda-se por normalidade a avaliação acerca do normal e do anormal, ou seja, é possível ocorrer tanto o aspecto positivo quanto o negativo. Já a avaliação da capacidade voltada para o julgamento que é feito acerca da pessoa avaliada quanto à sua competência e às suas habilidades. A tenacidade, por sua vez, é a avaliação no âmbito da disposição e da persistência do alvo da análise.

O grupo da sanção social divide-se em dois modos de expressar julgamento, conforme se pode observar no gráfico que segue:

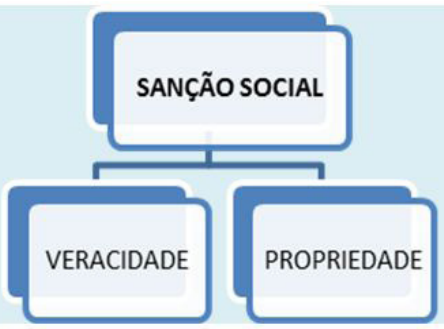

Fonte: Osias, 2011. 
No plano da veracidade, a pessoa é avaliada em sua honestidade e capacidade de ser verdadeira - ou não! Já a propriedade está voltada à ética - ou ausência dela! - no comportamento e nos valores da pessoa sob avaliação.

Quanto aos aspectos da concretização linguístico-discursiva do julgamento, vejamos a citação a seguir:

Quanto à realização do julgamento, WHITE (2001) mostra que o julgamento pode ser realizado por meio de advérbios, atributos e epítetos, grupos nominais ou na forma de verbos. (PEREIRA, 2010, p. 51)

O corpus escolhido, notícias de natureza policial recortadas de dois jornais locais, oferecem elementos vários para uma análise de julgamento, como veremos adiante, após os esclarecimentos sobre o jornal popular comentado a seguir.

\section{O JORNAL JÁ PARAÍBA}

O Jornal Já Paraíba, em formato de tabloide, surgiu no Sistema Correio de Comunicação no ano de 2009. Circula no Estado da Paraíba, sendo vendido ao preço de $R \$ 0,25$ (vinte e cinco centavos). Pelo valor, já se percebe que ele aponta para um público de menor poder aquisitivo, pertencente a classes sociais menos favorecidas. E não é apenas o valor que condiz com a possível classe social do leitor-alvo. A própria linguagem - não comprometida com a norma linguística vinculada à classe social de maior prestígio - é um indício claro da proposta do jornal: ser acessível a um público menos favorecido, levando informações por meio de uma linguagem que faz parte do universo linguístico desse público, ou seja, sem preciosismos gramaticais e sem dependência de uma norma culta exigida, exigente, imposta e excludente.

É relevante valorizar tal proposta, uma vez que a mídia, de uma forma geral, utiliza-se do espaço que tem para reiterar críticas ácidas aos usos linguísticos que não seguem à risca as rígidas regras gramaticais. A existência de um jornal como o Já Paraíba mostra-nos que modalidades linguísticas diversas podem coexistir, sem que isso represente a morte da língua portuguesa.

Segundo BAGNO (2008) apud OSIAS (2010), essa postura da mídia conservadora, a qual funciona como um dos Comandos Paragramaticais, sus- 
tenta-se por uma ideologia que considera a Gramática Tradicional como única forma aceitável de interação entre os falantes (por ser de prestígio), relegando os falares e outras performances da língua como manifestações toscas, inacabadas e, sobretudo, isentas de qualquer status e fomentando ideias em torno da reprodução de regras e da imposição de restrições, papel fundamental para a manutenção de um ciclo de controle de um saber linguístico oficial e unificado.

Esse tipo de jornal, como o Já Paraíba, em contrapartida, tem tido aumento de circulação, o que nos leva a constatar que mais pessoas de classes menos favorecidas estão tendo acesso à leitura, à informação, não importando se a linguagem utilizada é culta ou não, mas importando a funcionalidade dessa leitura.

É o que se pode observar no título da matéria publicada em 13 de julho de 2011 no Já Paraíba: "Choveu dinheiro em Alagoinha”. A escolha do emprego conotativo - e até jocoso - do verbo "chover" ilustra as afirmações aqui colocadas quanto ao não compromisso deste tabloide com imposições de um uso linguístico padrão e referencial, ocorrendo uma evidente adequação linguística ao contexto social do público-alvo.

Em outros Estados do Brasil, jornais semelhantes têm conquistado espaço igual, como podemos ver na citação a seguir: ${ }^{2}$

Os jornais populares se tornaram um fenômeno no Brasil. Entretanto, ninguém esperava que a venda desses periódicos se tornasse tão explosiva, desbancando os grandes veículos de comunicação que estão há anos no topo das tiragens. Esses novos dados foram divulgados pelo Instituto Verificador de Circulação (IVC), revelando que o tabloide mineiro Super Notícia, de Belo Horizonte, alcançava o primeiro lugar do ranking no mês de agosto, com aproximadamente 300 mil exemplares diários vendidos, desbancando a Folha de S.Paulo [...]. Na lista dos dez maiores jornais do país, o Super Notícia não é o único que segue a linha editorial popular. Outros títulos voltados, principalmente, às classes C e D também obtiveram destaque, como o Extra, do Rio de Janeiro, que ficou à frente do Estado de S.Paulo, e o Diário Gaúcho, do Rio Grande do Sul, que atingiu 152 mil exemplares. Preços baixos, muitas cores e imagens, linguagem curta e objetiva e excesso de publicidade

2 DIAS, Marina. Jornais populares explodem em vendas; São Paulo está fora da rota. In: Portal Imprensa, 28 de novembro de 2007. Disponível em <http:// www.direitoacomunicacao.org.br> Acesso em 24 jul. 2011. 
são imprescindíveis para o sucesso das publicações, é o que dizem os especialistas. [...] (DIAS, 2007). ${ }^{3}$

Tais considerações foram feitas com o intuito de esclarecer quanto à origem, à natureza e à proposta do tabloide mencionado.

\section{JORNAL CORREIO DA PARAÍBA}

O Correio da Paraíba teve como fundador Teotônio Neto, que, entre outras atuações, foi deputado federal pela Paraíba em várias legislaturas. A fundação deste jornal deu-se em 05 de agosto de 1953, estando, portanto, no cenário jornalístico local há quase seis décadas.

É o periódico de maior circulação na Paraíba e um dos mais tradicionais, mantendo a linha editorial alicerçada na norma culta da língua e fazendo observância à linguagem jornalística padrão, sem espaço para gírias ou regionalismos, por exemplo, com um público leitor pertencente, basicamente, às classes A e B, com médio ou alto grau de escolaridade.

\section{ANÁLISE DAS NOTÍCIAS}

A notícia recortada abaixo, intitulada Quadrilha explode em Alagoinha, foi publicada no caderno B6 do Jornal Correio da Paraíba, no dia 13 de julho de 2011, sob autoria da jornalista Ligia Coeli, correspondente de Campina Grande. Vejamos a notícia na íntegra:

3 Referência eletrônica, ausência de numeração de página. 


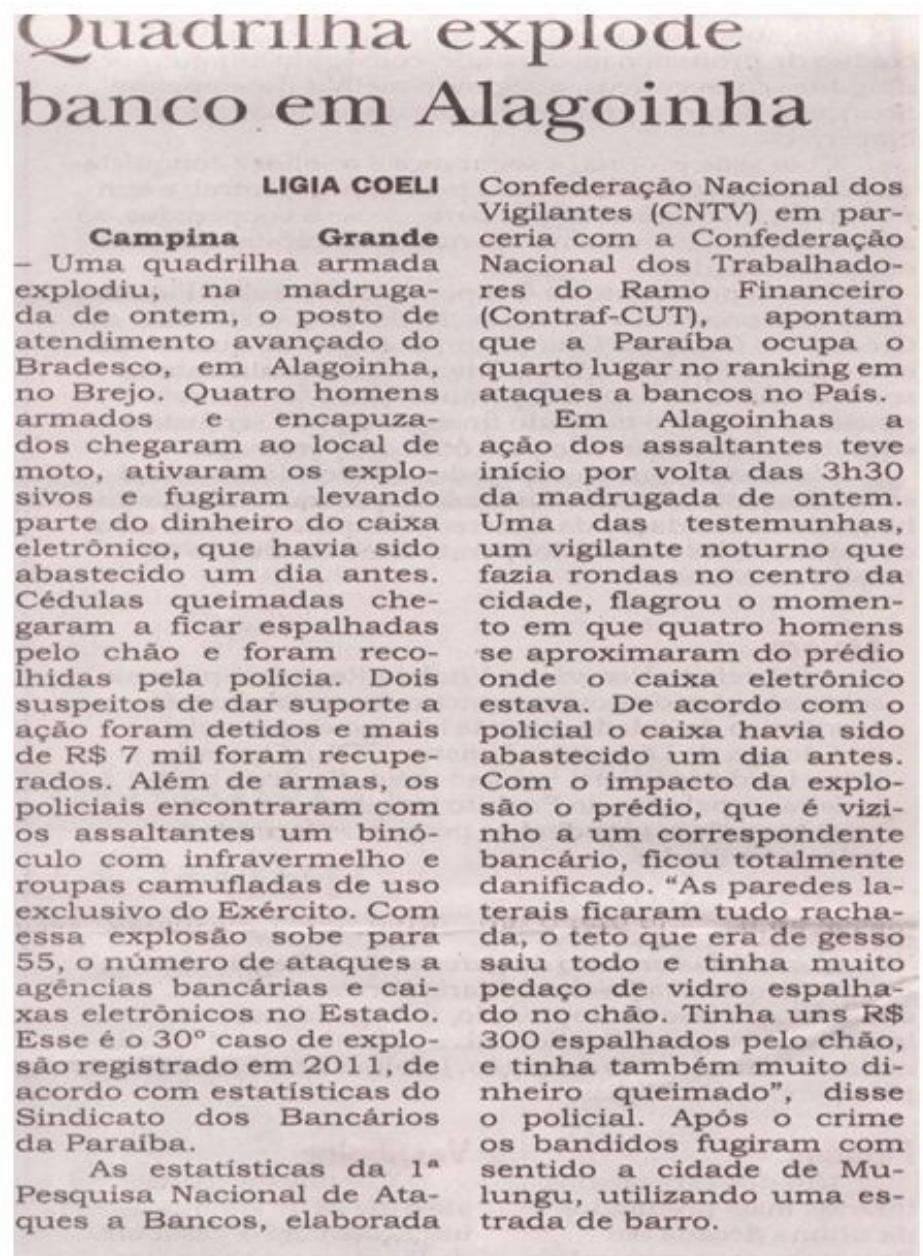

Fonte: Correio da Paraíba, 13 de julho de 2011.

Consideremos as análises, todas remetendo-se ao plano da propriedade, um dos modos de expressar julgamento no nível da sanção social:

\section{TRECHO:}

"Além de armas, os policiais encontraram com os assaltantes um binóculo com infravermelho e roupas camufladas de uso exclusivo do Exército". 
Ocorrência implícita de sanção social, com avaliação de propriedade negativa, deixando-se, nas entrelinhas, a reprovação, por parte do enunciador do texto, quanto ao fato de um equipamento dessa natureza ("binóculo com infravermelho e roupas camufladas de uso exclusivo do Exército") estar em mãos impróprias - nas dos assaltantes - ao invés de estar em mãos apropriadas - nas do Exército.

Outro fator que nos leva a perceber sanção social de propriedade é o adjetivo "exclusivo", utilizado para qualificar e determinar o substantivo "uso" - com relação a todo o equipamento utilizado pelos assaltantes -, significando uma ênfase na natureza militar daquele aparato. Como ele pode estar em poder não militar? Se ele é utilizado por pessoas não autorizadas, temos aqui uma situação descabida e, consequentemente, uma reprovação por parte do enunciador, baseada no consenso social e nas regras de conduta de toda uma sociedade.

Mais uma ocorrência de sanção social pode ser observada no trecho abaixo:

\section{2\% TRECHO:}

"Com essa explosão, sobe para 55 o número de ataques a agências bancárias e caixas eletrônicos no Estado. Esse é o $30^{\circ}$ caso de explosão registrado em 2011 [...]".

Em meio ao relato dos fatos, detecta-se, nas entrelinhas, outra sanção social implícita, perceptível a partir da crítica negativa acerca do índice absurdo de crimes idênticos ocorridos apenas no $1^{\stackrel{\circ}{ }}$ semestre! $\mathrm{O}$ enunciador do texto fez uso, mais uma vez, de críticas implícitas, reiterando sua reprovação e o ultraje da situação, uma vez que o número de manobras criminosas só tem aumentado, não havendo - ao que parece - ações policiais e/ou governamentais capazes de dirimir - ou, ao menos, reduzir - tal onda de assaltos.

\section{3- TRECHO:}

"[...] a Paraíba ocupa o quarto lugar no ranking em ataques a bancos no País." 
Avaliação de julgamento no gênero notícia: duas notícias, duas propostas jornalísticas...

Essa informação vai além do relato dos fatos: deixa subentendida uma questão inaceitável para o nosso Estado, o aumento da violência. É um ranking no qual nenhum Estado gostaria de estar, um ranking vergonhoso e amedrontador.

Há toda uma crítica quanto a vários fatores: falta de segurança e ausência de providências no sentido de se conter essa onda de assaltos e explosões, além de essa situação gerar uma imagem muito negativa para o Estado da Paraíba.

\section{TRECHO:}

"Após o crime os bandidos fugiram com sentido [...]."

Neste trecho, expressou-se julgamento, no nível da sanção social, apontando-se para uma questão, no mínimo, frustrante: a impunidade. Ou seja: os bandidos explodem o posto de atendimento, danificam totalmente o imóvel, queimam uma parte do dinheiro, levam outra parte e ainda escapam ilesos, tendo sido a fuga colocada como a culminância de todos os outros elementos mencionados anteriormente, nos trechos 1 a 3: uso indevido de certos equipamentos, alto índice de crimes de natureza idêntica num curto período e a "privilegiada" colocação no ranking da violência. 
Agora, o mesmo fato noticiado no jornal Já Paraíba:

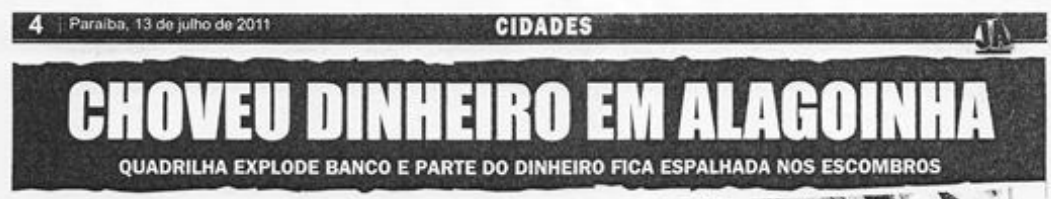

A gang da dinamite continua tos de dar suporte a aclo foram atacando com gosto de gas. Desta detidos e mais de RS 7 mil foram vez, a quadrilha armada explodiu, recuperados.

na madrugada de ontem, o posto De acordo com a Policia, alem de stendimento avançado do Bra. de amas, os policiais ercontrararn desco, na cidade de Alagoinha, no com os assantantes um binoculo Betio. Quatro homens armados $e$ com intravermetho e roupas camu Bre,o. Quaro homens armados e com intravemeno e rocosas camu encapuzados chegaram ao tocal fladas do uso exclusino do exticito. de moto, ativaram os explosivos Com easa explosá sobe para 55, e tugram levando parte do dininei- nimero de ataques a agencias bar. ro do caua eletronico, que havia carlas e cabas eletronicos no Esto Sido abastecico um dia antes. Ce Co. Esse e $030^{\circ}$ caso de explosád dulas queimadas chegaram a ficar regjstrado em 2011 , da acuevo com espandadss peio cháo e foram re. estatisicas do Sindicato dos Bancé colhidas pela policia. Dois suspei. rios da Pardiba,
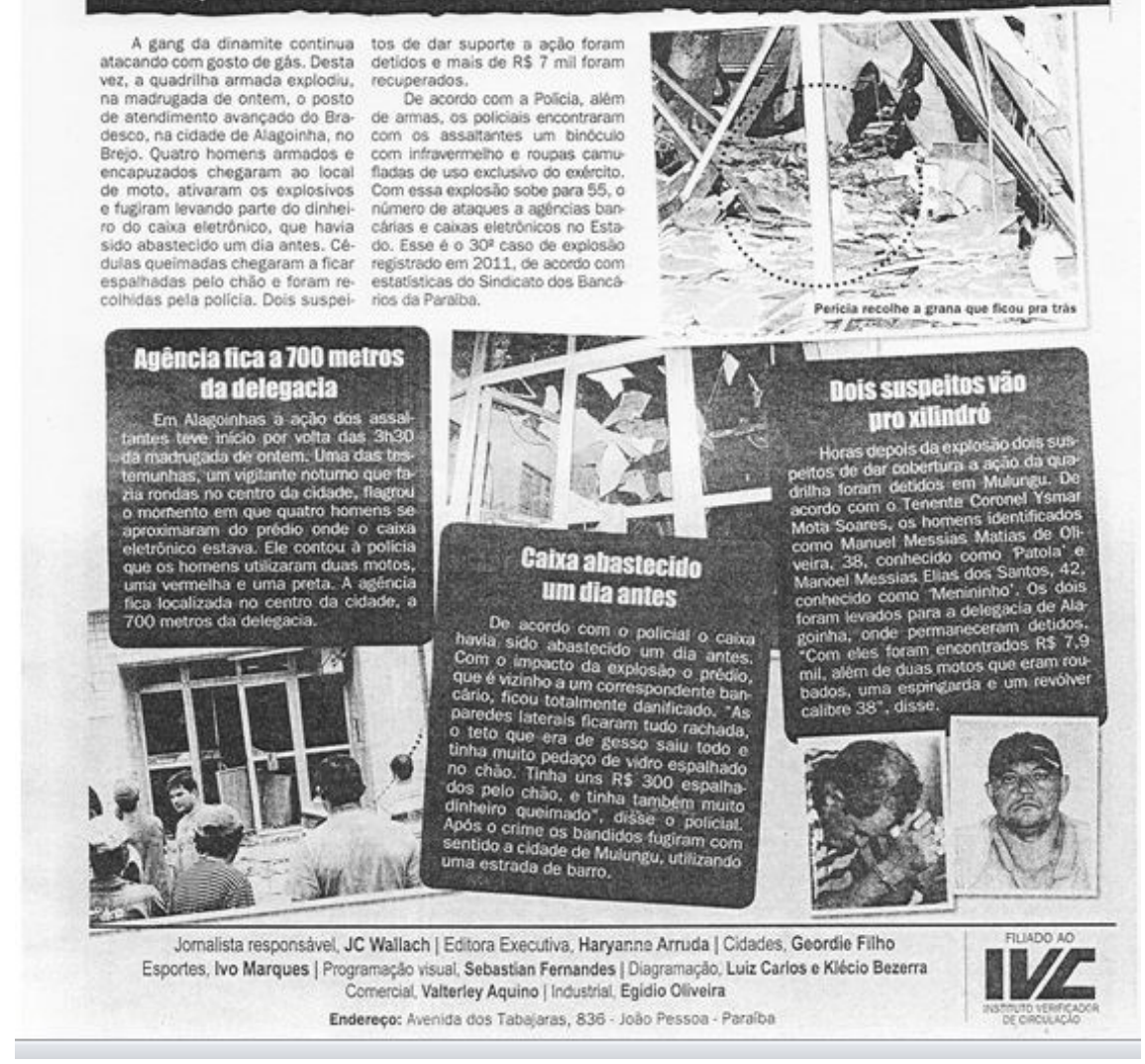

Fonte: Já Paraíba, 13 de julho de 2011.

Façamos as análises, todas direcionadas também ao plano da propriedade:

\section{TRECHO:}

"A gang da dinamite continua atacando com gosto de gás." 
Continuar atacando com gosto de gás denota, implicitamente, o caráter ininterrupto, quiçá cínico e destemido da gangue mencionada. Nada a detém - não há polícia capaz de fazê-lo. E ela age à solta, já sendo, inclusive, reconhecida como a "gang da dinamite" - já tem uma marca, uma identidade. Desta vez, o julgamento implícito de propriedade foi feito mediante uma linguagem figurada, além do caráter de variação linguística.

Vale ressaltar que o uso da linguagem figurada permite que o enunciador da notícia expresse com mais liberdade o julgamento negativo em questão. E o tom jocoso da expressão popular "gosto de gás" reitera essa liberdade.

\section{TRECHO:}

"A agência [explodida, atacada] fica localizada no centro da cidade, a 700 metros da delegacia."

Essa informação dá lugar a uma interpretação e, consequentemente, a um julgamento de propriedade por parte do enunciador da notícia: a falta de decoro e, principalmente, a audácia dos assaltantes! Isso deixa subentendida a avaliação negativa que se faz nesse trecho: como é possível uma ação criminosa desse porte tão próxima a uma delegacia? Ousadia por parte dos assaltantes... e inércia por parte dos policiais!

\section{3- TRECHO:}

"Dois suspeitos vão pro xilindró."

Este é um trecho que apresenta não apenas uma grafia não padrão - "pro" - como também o substantivo popularmente difundido, xilindró. Mais uma vez, o resultado soa um tanto cômico, e a comicidade está no fato de esta palavra em questão - xilindró - ter sido empregada em uma notícia cujo assunto é sério, uma notícia que não haverá de ser interpretada exatamente como "engraçada". Afinal, trata-se de uma ação violenta! Neste caso, o enunciador demonstra um certo prazer diante da captura dos dois suspeitos, em contrapartida à impunidade da fuga dos outros, que fugiram com o dinheiro roubado. 
Ao contrário do que ocorreu nos trechos anteriormente analisados, o enunciador sugere uma avaliação de caráter positivo, tendo aprovado a ação policial que deteve os dois suspeitos.

Em todos os casos analisados, é evidente, mesmo que de modo implícito, a atitude adotada pelo enunciador dos textos no que se refere a expressar seus julgamentos, quando alude a uma ética inexistente por parte dos criminosos, ou quando se refere a um fato positivo, como se viu na análise do $3^{\circ}$ trecho do Já Paraíba.

\section{CONSIDERAÇÕES FINAIS}

Observou-se, antes de tudo, a seguinte situação: a ocorrência da avaliação de propriedade, dentro do âmbito da sanção social, independe da variante linguística utilizada no discurso. No primeiro jornal analisado, Correio da Paraíba, a variante é padrão; no segundo caso, Já Paraíba, detectamos vários desvios da variante padrão, como é o caso de "gang" [sem que o termo esteja aportuguesado], "gosto de gás" e "choveu dinheiro". Nas duas variantes, no entanto, cada enunciador expressa, implicitamente, seus julgamentos de propriedade, analisando a ética (na verdade, a falta dela) e as ações desvirtuadas de uma gangue - ou mais de uma -, autora(s) de vários crimes.

Percebe-se, no entanto, um aspecto que nos pareceu mais vinculado à variante linguística de informalidade: um certo tom jocoso. Sim, pois até soa um tanto risível quando lemos que a gangue permanece agindo com "gosto de gás". "Chover dinheiro" também não parece uma ocorrência muito ortodoxa para uma notícia (a princípio, gênero caracterizado pela linguagem impessoal e objetiva). Este é um dado que nos parece relevante.

Outra conclusão a que chegamos foi que, independentemente da variação linguística, a expressão de julgamento (neste caso, de propriedade) pode ocorrer no gênero notícia, mesmo este sendo estruturado numa linguagem imparcial e objetiva, utilizando-se da tipologia narrativa, não comportando, a priori, nenhum tipo de subjetividade por parte do escrevente. Ou seja, teoricamente, o gênero notícia apresenta configuração e função social voltadas 
para o relato dos fatos e, no máximo, a descrição de pessoas, situações e ambientes, por exemplo.

Daí, então, a implicitude das avaliações de julgamento observadas em ambos os textos. Nos casos analisados, as ocorrências de avaliações por parte dos escreventes, no âmbito da sanção social, deram-se de modo a extrapolar a configuração e a função do gênero em questão, a notícia.

\section{BIBLIOGRAFIA}

ALMEIDA, F. S. D. P. 2010. Atitude: afeto, julgamento e apreciação. In: VIAN JR. O.; SOUZA, A. A.; ALMEIDA, F. S. D. P. A linguagem da avaliaģão em lingua portuguesa - Estudos sistêmico-funcionais com base no Sistema de Avaliatividade. São Carlos: Pedro \& João Editores. 99-112.

BAGNO, M. 2008. Dramática da língua portuguesa: tradição gramatical, mídia \& exclusão social. São Paulo: Loyola.

COELI, Ligia. Quadrilha explode banco em Alagoinha. Jornal Correio da Paraíba, caderno B6, 13 de julho de 2011.

DIAS, M. Jornais populares explodem em vendas, São Paulo está fora da rota. In: Portal Imprensa, 28 de novembro de 2007. Disponível em: <http:/ / www.direitoacomunicacao.org.br>. Acesso em 24 jul. 2011.

LIMA, S.; COROA, M. L. M.S. 2010. Configuracãa e papel do sistema de avaliatividade no gênero reportagem. Calidoscópio v. 8, n. 2. 127-137.

OSIAS, J. P. de A. 2010. Jornal Já Paraíba: quebrando paradigmas no ciclo midiático do preconceito linguístico. Revista Eletrônica Temática, Ano VI, n. 09.

PEREIRA, E. B. 2011. O professor avaliado em textos jornalísticos: análise da avaliatividade em reportagens de Veja e Istoé. Dissertação de mestrado.

\section{Evaluation of judgment in the new genre: two news stories, two journalistic strategies, one single appraisal}

\footnotetext{
Abstract: Two news stories, published in two local newspapers - Correio da Paraíba and Já Paraíba -, were analyzed, based on the appraisal system, developed from principles of Systemic Functional Linguistics, in particular the category of judgment (one of the regions of the sub-system attitude), in the social norms group. An appraisal analysis was carried out within the scope of a theoretically narrative discursive genre, as well as the occurrence of this appraisal
} 
independently of linguistic variations (an aspect emphasized by the fact that the two newspapers in this study have opposing linguistic approaches), through a comparative reading.

Keywords: Attitude; Judgment; Systemic Functional Linguistics; News; Appraisal System.

Recebido em: 23/10/2011

Aprovado em: 15/03/2012 